\title{
Analysis of Conducted and Radiated Noise of Soft-Switched Flyback DC-DC Converter
}

\author{
G. Spiazzi*, A. Zuccato**, P. Tenti* \\ *Department of Electronics and Informatics \\ University of Padova \\ Via Gradenigo 6/a, 35131 Padova - ITALY \\ Phone: +39-49-827.7525 Fax: +39-49-827.7599/7699 \\ E-Mail: giorgio@tania.dei.unipd.it \\ ** CREI Ven Research Consortium in Industrial Electronics \\ C.so Spagna 12 - 35100 Padova - ITALY \\ E-Mail: creiven@iperv.it
}

\begin{abstract}
This paper is aimed to the design of soft-switched flyback DC-DC converters taking into account conducted and radiated emission noise aspects.

In fact, by a proper system design, the use of an active voltage clamp in flyback converters may result in reduced voltage stresses, soft switching of the main devices, and improved EMI.

The paper discusses different design aspects and their impact on the generated noises. Theoretical results are confirmed by experimental measurements.
\end{abstract}

\section{INTRODUCTION}

Aspects regarding Electro-Magnetic Interferences (EMI) in power electronics are gaining a considerable attention due to the more and more stringent requirements sets by international standards. The design of power converters must take into account these problems from the beginning, and this means that also the choice of converter topology should be done according to EMI requirements.

From this point of view, the use of soft switching techniques, besides the decreasing of commutation losses, allows a reduction of conducted and radiated noise. This result is accomplished by reduction of high voltage and current rate of changes, and elimination of high frequency ringing due to converter parasitics.

However, in many cases, in order to achieve the soft-switching condition, the current stresses are increased, thus adversely affecting the differential mode noise generation. This means that many design aspects must be taken into account in order to effectively gain advantage from the use of soft switching techniques.

In this paper the behavior of a soft-switched flyback DCDC converter with active clamp is investigated as far as generation of electromagnetic noise is concerned [1-4]. In particular, conducted noise is measured by means of a passive probe in the frequency range from $150 \mathrm{kHz}$ to $30 \mathrm{MHz}$, and radiated noise is measured in an anechoic chamber with standard setup and instrumentation for frequencies from $30 \mathrm{MHz}$ to $1 \mathrm{GHz}$.

Several design aspects are considered and their inpact on the produced noise investigated. Moreover, the use of the same prototype (and thus same layout) allows a meaningful comparison between soft-switching and hard-switching conditions by simply increasing the output capacitance of the mosfets up to the value for which soft-switching condition is lost.

\section{REVIEW OF THE FLYBACK CONVERTER WITH ACTIVE CLAMP}

In this section, the behavior of the flyback converter with active clamp, shown in Fig. 1, is reviewed both for Discontinuous and Continuous Conduction Mode.

The inductance $\mathrm{L}_{\mathrm{R}}$ includes the transformer leakage inductance while $\mathrm{C}_{\mathrm{P}}$ accounts for the switch output capacitance. In the following analysis, ideal switching components are assumed.

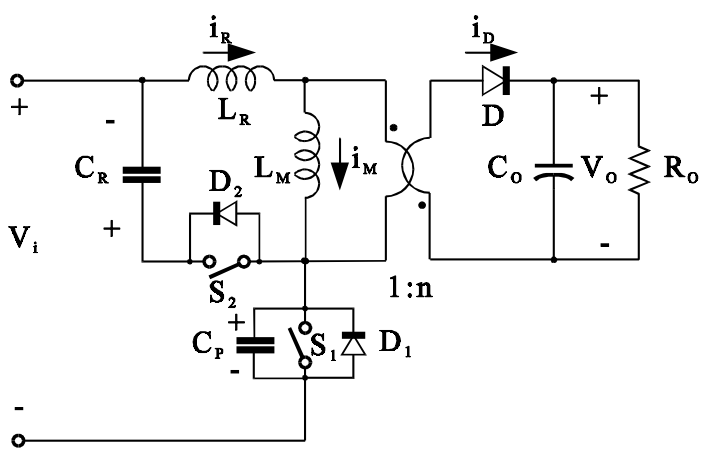

Fig.1 - Flyback converter with active clamp 


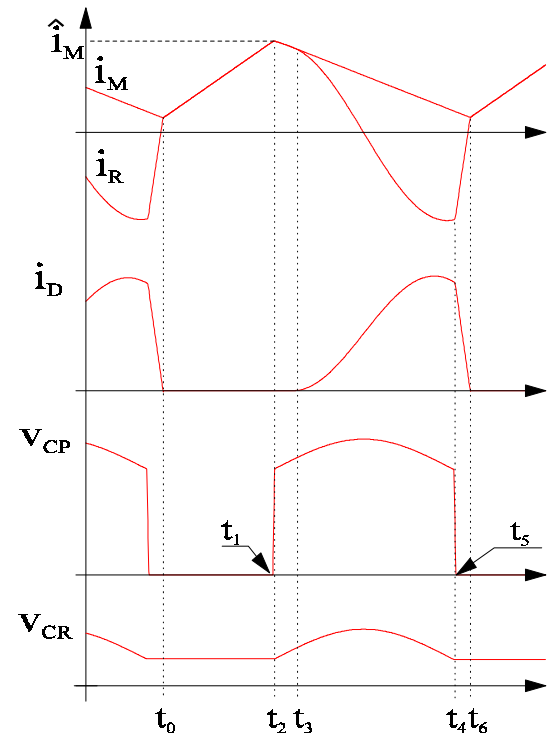

Fig. 2 - Main converter waveforms in CCM operation

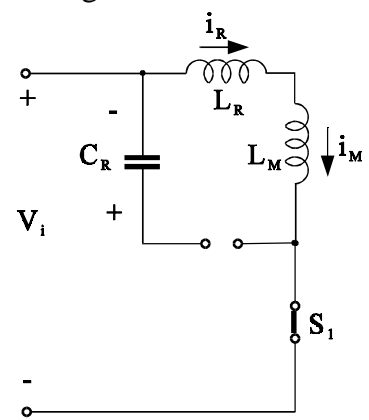

a)

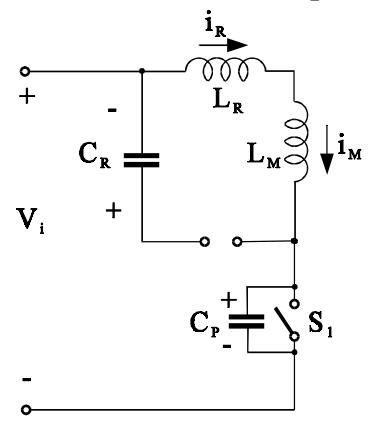

b)

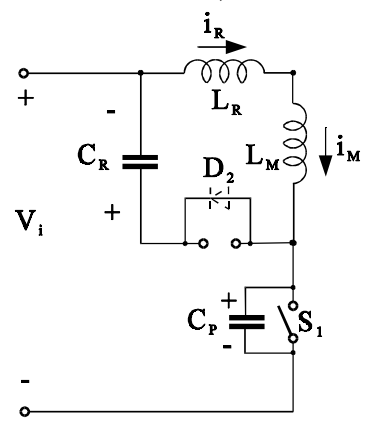

c)

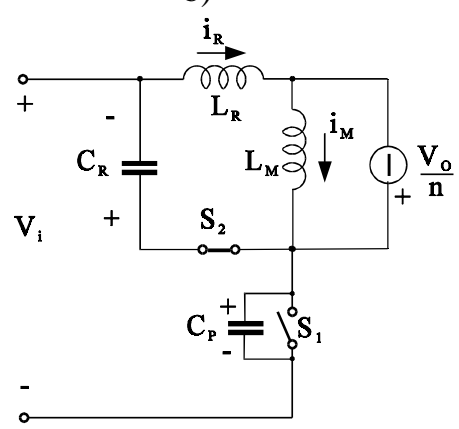

d)

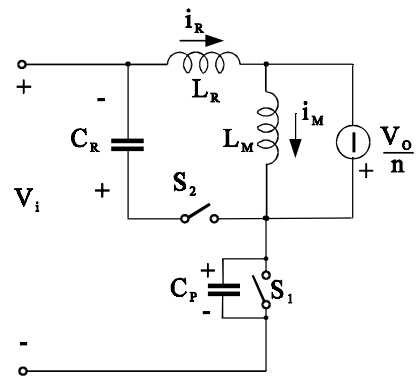

e)

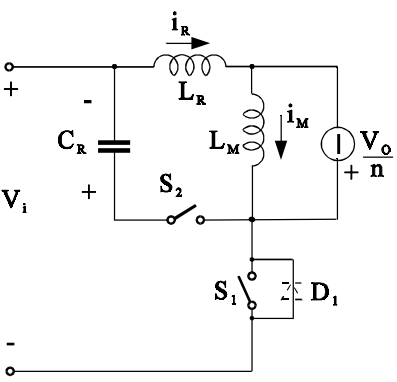

f)
Fig.3 - Subtopologies corresponding to different switch states

\section{A. Continuous Conduction Mode (CCM)}

As can be seen in Fig. 2, which shows main converter waveforms in CCM, each switching period is subdivided into six intervals, each of them corresponds to a different topology (see Fig. 3). In the following, only a qualitative analysis of the converter behavior in these intervals is given, while a more complete explanation can be found in [4].

1) Interval $t_{0^{-}} t_{1}$ (Fig.3a): At instant $t_{0}$ the freewheeling diode $D$ stops conduction and switch $S_{1}$ is on while switch $S_{2}$ is off. The currents in the leakage inductance $L_{R}$ and in the magnetizing inductance $\mathrm{L}_{\mathrm{M}}$ are equal and increase linearly with a slope dependent on the input voltage.

2) Interval $t_{1}{ }^{-t_{2}}$ (Fig.3b): At instant $\mathrm{t}_{1} \mathrm{~S}_{1}$ is turned off and $\mathrm{C}_{\mathrm{P}}$ is charged almost linearly by the magnetizing inductance current until, at instant $t_{2}$, its voltage equals $\mathrm{V}_{\mathrm{i}}+\mathrm{V}_{\mathrm{C}_{\mathrm{R} 0}}$ and diode $\mathrm{D}_{2}$ starts conducting $\left(\mathrm{V}_{\mathrm{C}_{\mathrm{R} 0}}\right.$ is the initial value of the voltage across the resonant capacitor $C_{R}$ ). Thus, the voltage rate of change across the Mosfets is linearly dependent on the magnetizing current value at instant $t_{1}$, which is the peak magnetizing current.

3) Interval $t_{2}^{-t_{3}}$ (Fig.3c): After conduction of $\mathrm{D}_{2}$, inductors $L_{R}$ and $L_{M}$ resonate with capacitors $C_{R}$ and $C_{P}$ until the transformer secondary voltage becomes greater than the output voltage and the freewheeling diode starts conducting (instant $\mathrm{t}_{3}$ ).

4) Interval $t_{3}$ - $_{4}$ (Fig.3d): During this interval the magnetizing inductance current decreases linearly with a slope dependent on the reflected output voltage $\mathrm{V}_{o p}=\mathrm{V}_{\mathrm{o}} / \mathrm{n}$, transferring energy to the output, while $\mathrm{L}_{\mathrm{R}}$ resonates with $\mathrm{C}_{\mathrm{R}}$. The maximum voltage stress across the switches occurs during this interval and depends on the value of the characteristic impedance and on the initial condition in the resonant elements. In [4] it was shown that an approximate value of the voltage stress is given by:

$$
\hat{\mathrm{v}}_{\mathrm{S}_{1}}=\mathrm{V}_{\mathrm{i}}+\mathrm{v}_{\mathrm{C}_{\mathrm{R}, \mathrm{MAX}}} \cong \mathrm{V}_{\mathrm{i}}+\mathrm{V}_{\mathrm{op}}+\mathrm{Z}_{2} \cdot \hat{\mathrm{i}}_{\mathrm{M}}
$$

where

$$
\mathrm{Z}_{2} \cong \sqrt{\frac{\mathrm{L}_{\mathrm{R}}}{\mathrm{C}_{\mathrm{R}}}}
$$

Note that the auxiliary switch $\mathrm{S}_{2}$ is turned on in lossless manner before the clamp capacitor current reverses.

5) Interval $t_{4}{ }^{-} t_{5}$ (Fig.3e): At instant $\mathrm{t}_{4} \mathrm{~S}_{2}$ is turned off and $\mathrm{L}_{\mathrm{R}}$ resonates with $\mathrm{C}_{\mathrm{P}}$ bringing its voltage to zero (assuming it has enough energy) and forcing the conduction of $\mathrm{D}_{1}$ (instant $\mathrm{t}_{5}$ ). At the same time the magnetizing current continues to decrease linearly. 
6) Interval t5-t6 (Fig.3f): The current in $\mathrm{L}_{\mathrm{R}}$ increases linearly with a slope proportional to $\mathrm{V}_{\mathrm{i}}+\mathrm{V}_{\mathrm{op}}$ and, at the same time, the freewheeling diode current, which is equal to the difference between magnetizing and resonant inductor currents reflected to the secondary side, decreases to zero with almost the same slope.

Note that $S_{1}$ must be turned on when $i_{R}$ is still negative in order to obtain a zero voltage turn on. At $t_{6}$ current $i_{R}$ becomes equal to the magnetizing current $\mathrm{i}_{\mathrm{M}}$ (which was still linearly decreasing), and the freewheeling diode D stops conduction, initiating another switching cycle.

\section{B. Discontinuous Conduction Mode (DCM)}

Fig. 4 reports the main waveforms of the same converter taken at $5 \%$ of rated power. The only difference in the operational sequence is that interval $\mathrm{t}_{3}-\mathrm{t}_{4}$ is terminated by the turn off of the freewheeling diode $D$ while $S_{2}$ is still on. After that, $L_{R}$ and $L_{M}$ resonate with $C_{R}$ until $S_{2}$ is turned off (instant $\mathrm{t}_{5}$ ). Then, $\mathrm{L}_{\mathrm{R}}$ and $\mathrm{L}_{\mathrm{M}}$ together resonate with $\mathrm{C}_{\mathrm{P}}$, bringing its voltage to zero (instant $t_{6}$ ) and initiating another switching cycle.

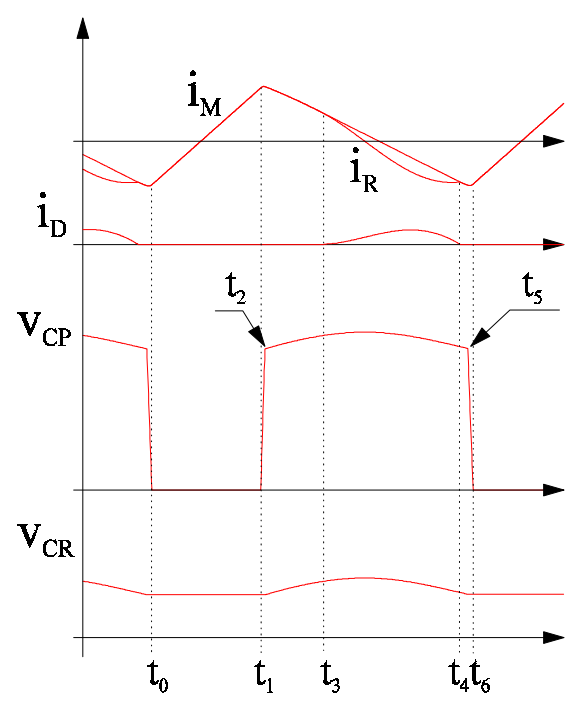

Fig.4 - Main converter waveforms in DCM operation

\section{SIMPLIFIED CONVERTER ANALYSIS}

As we can see from the wafeforms of Figs. 2 and 4, the behavior of the flyback converter with active clamp is quite different respect to the hard switched counterpart. However, using suitable approximations, it is possible to derive useful relations which can greatly simplify the design procedure. First of all, as far as the conversion ratio is concerned, if we consider $\mathrm{L}_{\mathrm{R}} \ll<\mathrm{L}_{\mathrm{M}}$ we can see that the voltage across the magnetizing inductance $L_{M}$ is equal to $V_{i}$ during the switch on-time while during the switch off-time it changes from $V_{o p}$ (interval $t_{3}-t_{4}$ ) to $v_{C_{R}}$ during interval $t_{2}-t_{3}$ (and also $t_{4}{ }^{-t_{5}}$ in DCM). Since $v_{C_{R}}$ value in these intervals is close to $v_{o p}$ and considering that the duration of these interval is small compared to that of interval $t_{3}-t_{4}$, we have from the voltage balance on $\mathrm{L}_{\mathrm{M}}$ :

$$
\mathrm{M}=\frac{\mathrm{V}_{\mathrm{op}}}{\mathrm{V}_{\mathrm{i}}} \cong \frac{\delta}{1-\delta}
$$

which is the same of the standard flyback converter. Note that the same expression holds for both CCM and DCM operating modes.

The average current $I_{M}$ in the magnetizing inductance, assuming unity efficiency, is given by:

$$
\mathrm{I}_{\mathrm{M}}=\mathrm{I}_{\mathrm{i}}+\mathrm{nI}_{\mathrm{o}}=\mathrm{nI}_{\mathrm{o}}(1+\mathrm{M})
$$

while its current ripple amplitude is:

$$
\Delta i_{M}=\frac{V_{i}}{L_{M} f_{S}} \cdot \delta=\frac{V_{o p}}{L_{M} f_{S}} \cdot \frac{1}{1+M}
$$

where $f_{S}$ is the switching frequency. From (4) and (5) the peak inductor current results:

$$
\hat{\mathrm{i}}_{\mathrm{M}}=\mathrm{i}_{\mathrm{M}}\left(\mathrm{t}_{1}\right)=\mathrm{I}_{\mathrm{M}}+\frac{\Delta \mathrm{i}_{\mathrm{M}}}{2}=n \mathrm{I}_{\mathrm{o}} \cdot\left[1+\mathrm{M}+\frac{1}{\mathrm{k}(1+\mathrm{M})}\right]
$$

where

$$
\mathrm{k}=\frac{2 \mathrm{~L}_{\mathrm{M}} \mathrm{f}_{\mathrm{S}}}{\mathrm{R}_{\mathrm{op}}}=\frac{2 \mathrm{~L}_{\mathrm{M}} \mathrm{f}_{\mathrm{S}} \mathrm{n}^{2}}{\mathrm{R}_{\mathrm{o}}}
$$

is the usual parameter used in the flyback analysis.

The discontinuous mode of operation is reached when at instant $\mathrm{t}_{4}$ resonant inductor current $\mathrm{i}_{\mathrm{R}}$ and magnetizing current $i_{M}$ are equal. The analysis done in [4] shows that this happens in the correspondence of the value of the critical parameter $\mathrm{k}_{\mathrm{crit}}$ given by the following expression:

$$
\mathrm{k}_{\text {crit }}=\frac{1-|\cos (\varepsilon)|}{1+|\cos (\varepsilon)|} \cdot \frac{1}{(1+\mathrm{M})^{2}}
$$

where

$$
\varepsilon=\omega_{2} \mathrm{~T}_{34} \text { and } \mathrm{T}_{34}=\mathrm{t}_{3}-\mathrm{t}_{4} \approx(1-\delta) \mathrm{T}_{\mathrm{S}} .
$$

This means that the converter enters in DCM at a fraction $\alpha$ of the nominal output power, given by:

$$
\alpha=\mathrm{R}_{\text {op }} \cdot \frac{\mathrm{k}_{\text {crit }}}{2 \mathrm{~L}_{\mathrm{M}} \mathrm{f}_{\mathrm{S}}}
$$

\section{ZERO VOLTAGE SWITCHING CONDITION}

The analysis reported in section II, shows that in CCM operation only the energy stored in the leakage inductance at instant $\mathrm{t}_{4}$ plays a role in discharging the mosfet parasitic capacitance $\mathrm{C}_{\mathrm{P}}$, while in DCM operation also the magnetizing inductance $\mathrm{L}_{\mathrm{M}}$ is involved in this process (instant $t_{5}$ ). Thus, the condition to obtain zero voltage commutation depends on the operating mode. As 
demonstrated in [4], when the converter operates in CCM, the soft switching condition is ensured if the converter parameter satisfy the following constraint:

$$
\sqrt{\frac{\mathrm{L}_{\mathrm{R}}}{\mathrm{C}_{\mathrm{P}}}} \geq \frac{2 \mathrm{~L}_{\mathrm{M}} \mathrm{f}_{\mathrm{S}}}{\mathrm{M}} \cdot \frac{(1+\mathrm{M})^{2}}{1+\mathrm{k}(1+\mathrm{M})^{2}} \cdot \frac{1}{|\cos (\varepsilon)|}
$$

The minimum value of $L_{R}$ is obtained for $\varepsilon=0$.

Note that if inductance $\mathrm{L}_{\mathrm{R}}$ is designed so as to meet the above inequality for $\mathrm{k}=0$, then the ZVS condition should be maintained in all the load range.

When the converter operates in DCM, the inequality that must be satisfied becomes:

$$
\sqrt{\frac{L_{M}}{C_{P}}} \geq \frac{2 L_{M} f_{S}}{M} \cdot \frac{(1+M) \cdot \sqrt{1-M^{2}}}{\left|k(1+M)^{2}-1\right|}
$$

\section{DESIGN CONSIDERATIONS}

As we can see from the above analysis all converter parameters influence several aspects of the converter behavior. Thus, the choice of their values is necessarily a trade off between stresses, conduction losses, need to guarantee the soft commutation, etc.

To this purpose, we can not forget thet, in order to obtain the correct converter behavior, suitable switch drive signal must be generated; in particular, dead times between turn off of $S_{1}$ and turn on of $S_{2}$ and vice versa, are needed in order to allow for complete charge and discharge of parasitic capacitance $\mathrm{C}_{\mathrm{P}}$.

Besides these aspects, considerations regarding the elettromagnetic noise generated must be also taken into account since one of the main advantage of using soft switching converters should be the reduction of the electromagnetic pollution.

\section{A. Magnetizing Inductance}

The choice of the magnetizing inductance influences both the ZVS condition (as can be seen from eqs. (11) and (12) and current and voltage stresses on the main switch. In fact, the switch current stress is equal to the peak inductor current reported in (6) while the switch voltage stress is given by (1). From this latter, we observe that also $\mathrm{Z}_{2}$ depends on the magnetizing inductance value through the soft switching condition (11), but it can be demonstrated that their product decreases at lower inductance values.

Once the desired current ripple in $\mathrm{L}_{\mathrm{M}}$ is chosen, its value can be calculated by using (5). Thus, a high magnetizing inductance values gives:

Advantages:

- low peak current stress in the switch

- low RMS current in inductors and main switch, i.e. low conduction losses

Drawbacks:
- $\quad$ high magnetizing inductor size

- high resonant inductor value in order to maintain the soft commutation

- $\quad$ high switch voltage stress

- high delay time between turn off of $S_{1}$ and turn on of $S_{2}$ (interval $\mathrm{t}_{1}-\mathrm{t}_{2}$ )

\section{B. Resonant inductance $L_{R}$}

In [4], a procedure to derive the resonant inductor value was proposed, which allow soft commutation in all operating conditions. However, we must be aware of the effects that this inductance value has on other converter performances. In fact, we can say that a high resonant inductor value gives:

\section{Advantages:}

- $\quad$ low switch voltage stress (see (1) and (2))

- low di/dt in the freewheeling diode at turn off (interval $\left.\mathrm{t}_{5}-\mathrm{t}_{6}\right)$

Drawbacks:

- high resonant inductor size

- $\quad$ high switch voltage stress

- high delay time between turn off of $S_{2}$ and turn on of $S_{1}$ (interval $\mathrm{t}_{4}-\mathrm{t}_{5}$ )

\section{Resonant Capacitor $C_{R}$}

The value of resonant capacitor $C_{R}$ is determined by the resonant period in the interval $t_{3}-t_{4}$, thus from the value of angle $\varepsilon$ defined in [9]. We can summerize its main effects on the converter behavior saying that a high resonant capacitor value gives:

\section{Advantages:}

- possibility to increase snubber capacitor $\mathrm{C}_{\mathrm{P}}$ which reduces the $\mathrm{dv} / \mathrm{dt}$ across the switches

Drawbacks:

- high resonant inductor value in order to meet the ZVS condition (11) (because of a reduced $\varepsilon$ value)

\section{Capacitor $C_{P}$}

This capacitance usually represents the sum of the parasitic output capacitances of $S_{1}$ and $S_{2}$ and of the frewheeling diode (reported to the primary side of the transformer). In some applications, it could be convenient to increase this capacitance by adding an external one in order to limit the maximum voltage rate of change across the active devices and thus to reduce both conducted and radiated disturbances. Moreover, this provision can be indispensable when IGBT are used instead of mosfets in order to reduce their turn off losses due the tail current phenomenon. Once again, we can summerize the effects of a high CP value as follows: 
Advantages:

- $\quad$ low dv/dt across the switches

- low turn off losses

Drawbacks:

- $\quad$ high resonant inductor value in order to maintain the soft commutation

- high switch voltage stress (as a consequence of the previous point)

- high delay times between turn off of one switch and turn on of the other

\section{EXPERIMENTAL MEASUREMENTS}

We want now to investigate the inpact of the previous design considerations from the EMI point of view. To this purpose three different converter designs were selected whose parameters are reported in Table I through Table III.

Table I - Converter \#1 specifications and parameters ( $\mathbf{L}_{\mathbf{R}}$ is an external inductor)

\begin{tabular}{||c|c|c|c||c||}
\hline \hline $\mathrm{V}_{\mathrm{i}}=100 \mathrm{~V}$ & $\mathrm{~V}_{\mathrm{O}}=48 \mathrm{~V}$ & $\mathrm{f}_{\mathrm{s}}=300 \mathrm{kHz}$ & $\mathrm{L}_{\mathrm{R}}=3.8 \mu \mathrm{H}$ & $\mathrm{L}_{\mathrm{M}}=25 \mu \mathrm{H}$ \\
\hline $\mathrm{C}_{\mathrm{O}}=100 \mu \mathrm{F}$ & $\mathrm{n}=1$ & $\mathrm{R}_{\mathrm{L}}=24 \Omega$ & $\mathrm{C}_{\mathrm{R}}=76 \mathrm{nF}$ & $\mathrm{C}_{\mathrm{P}}=0.4 \mathrm{nF}$ \\
\hline
\end{tabular}

Table II - Converter \#2 specifications and parameters ( $L_{R}$ is the transformer leakage inductance)

\begin{tabular}{||c|c|c|c||c||}
\hline $\mathrm{V}_{\mathrm{i}}=100 \mathrm{~V}$ & $\mathrm{~V}_{\mathrm{O}}=48 \mathrm{~V}$ & $\mathrm{f}_{\mathrm{S}}=300 \mathrm{kHz}$ & $\mathrm{L}_{\mathrm{R}}=3 \mu \mathrm{H}$ & $\mathrm{L}_{\mathrm{M}}=25 \mu \mathrm{H}$ \\
\hline $\mathrm{C}_{\mathrm{O}}=100 \mu \mathrm{F}$ & $\mathrm{n}=1$ & $\mathrm{R}_{\mathrm{L}}=24 \Omega$ & $\mathrm{C}_{\mathrm{R}}=132 \mathrm{nF}$ & $\mathrm{C}_{\mathrm{P}}=0.4 \mathrm{nF}$ \\
\hline
\end{tabular}

$\mathrm{L}_{\mathrm{M}}$ : Core $\mathrm{RM} 10, \mathrm{~N}_{1}=\mathrm{N}_{2}=8$ turns litz wire

Table III - Converter \#3 specifications and parameters ( $L_{\mathbf{R}}$ is an external inductor plus transformer leakage inductance)

\begin{tabular}{||c|c|c|c|c||}
\hline $\mathrm{V}_{\mathrm{i}}=100 \mathrm{~V}$ & $\mathrm{~V}_{\mathrm{o}}=48 \mathrm{~V}$ & $\mathrm{f}_{\mathrm{s}}=300 \mathrm{kHz}$ & $\mathrm{L}_{\mathrm{R}}=6 \mu \mathrm{H}$ & $\mathrm{L}_{\mathrm{M}}=72 \mu \mathrm{H}$ \\
\hline $\mathrm{C}_{\mathrm{O}}=100 \mu \mathrm{F}$ & $\mathrm{n}=1$ & $\mathrm{R}_{\mathrm{L}}=24 \Omega$ & $\mathrm{C}_{\mathrm{R}}=76 \mathrm{nF}$ & $\mathrm{C}_{\mathrm{P}}=0.4 \mathrm{nF}$ \\
\hline
\end{tabular}

$\mathrm{L}_{\mathrm{M}}$ : Core E3213A, $\mathrm{N}_{1}=\mathrm{N}_{2}=14$ turns litz wire

Converter \#1 is designed to meet the ZVS condition in all the load range by using a tight coupled transformer plus an external resonant inductor $\mathrm{L}_{\mathrm{R}}$.

Converter \#2 also provides soft commutation in all operating conditions but it uses a transformer built to have the desired leakage inductance, without need of an external one. Resonant inductor current $i_{\mathrm{LR}}$, main switch drain-to-source voltage $v_{D S 1}$ and gate-to-source voltage $v_{\text {GS1 }}$ waveforms relative to this converter are reported in Fig. 5 at rated power: the soft-switching condition is easily recognized.

Converter \#3 was designed to have a much greater magnetizing inductance with the same external resonant inductor as converter \#1. Thus, the total $L_{R}$ value is equal to $6 \mu \mathrm{H}$ and it is not enough to guarantee the soft commutation in all the load range.

Radiated test has been performed in an anechoic chamber adapted for radiated emission tests in the range $30 \mathrm{MHz}-1 \mathrm{GHz}$ measuring both horizontal and vertical components of the electric field, while a shielded chamber was used for conducted emissions. The employied receiver was the HP8542E (full compliance with CISPR 16-1 standard). The measurements were performed with the antenna located at 3 meter distance from the device under test.

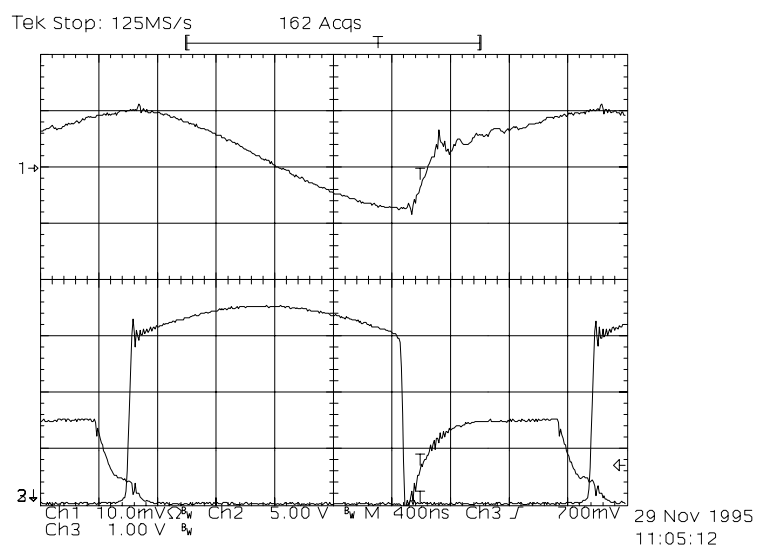

Fig.5 - Resonant inductor current $i_{L R}$, main switch drain-to-source voltage $\mathrm{V}_{\mathrm{DS} 1}$ [50V/div] and gate-to-source voltage $\mathrm{V}_{\mathrm{GS} 1}$ [10V/div] measured on converter \#2; (i ${ }_{\mathrm{LR}}[5 \mathrm{~A} / \mathrm{div}], \mathrm{I}_{\mathrm{O}}=2 \mathrm{~A}$ )

\section{A) Effects of transformer secondary leakage inductance}

In order to evaluate the effects of the ringings due to the transformer secondary leakage inductance the radiated noise of converter \#1 was measured with and without a secondary R-C snubber (220 $\Omega-250 \mathrm{pF}$ across the freewheeling diode). The results are reported in Fig. 6a) and b) which show measurements of the horizontal field. We can see that without secondary snubber, there is a general worsening of the generated noise in the frequency range of $100-300 \mathrm{MHz}$ and this is confirmed also by the vertical field measurement (not shown).

This behavior is confirmed by conducted noise measurement done on converter \#2 with a current probe Rohde \& Schwarz EZ-17, whose results are shown in figs. 8a) and $b$ ): the peak around $10 \mathrm{MHz}$ is indicative of an increased secondary ringing.

B) Effects of transformer primary leakage and magnetizing inductance

One of the first design choice we have to make regards the transformer construction, i.e. we have to decide the value of 
magnetizing inductance and if it is preferable to have a tight coupled transformer plus an external resonant inductor (converter \#1) or to build the transformer with the desired leakage inductance (converter \#2).

As far as magnetizing inductance is concerned, comparison of figs. 6b) and c) with fig. 6d) show a better behavior of converter \#3 which becomes much more evident looking at the measurements with vertical polarity (not shown). Note also that the lower current ripples and stresses, consequence of a higher $\mathrm{L}_{\mathrm{M}}$ value, reduce the conduction losses. Instead, comparison between converter \#1 and \#2 (figs. 6b) and c) respectively) does not give clear results because from the horizontal field measurement converter \#2 shows a better behavior for frequencies above $120 \mathrm{MHz}$ but it is worse than converter \#1 at lower frequency and also from the vertical field measurement (not shown). To evaluate this result we must observe that the transformer of converter \#1 is built using an E core while that of converter \#2 is an RM core having a lower leakage flux. Thus, converter \#1 should be preferable because a not tight coupled transformer have higher secondary leakage inductance and leakage flux than a tight coupled one.

\section{C) Effects of an increased capacitance $C_{P}$}

An external capacitance between drain and source of the main mosfet increases the value of $C_{P}$ and thus reduces the $\mathrm{dv} / \mathrm{dt}$ across the switches. If this does not impair the soft switching condition, it should improving the converter performances in terms of EMI. Let us compare figs. 6e) and f), which show measurements taken on converter \#3 with an external capacitor between drain and source of the main mosfet of $500 \mathrm{pF}$ and $1 \mathrm{nF}$ respectively, with fig. $6 \mathrm{~d}$ ). As we can see below $\approx 150 \mathrm{MHz}$ we can note an improvement due to the increase of $\mathrm{C}_{\mathrm{P}}$ value but a sensible worsening at higher frequencies (the vertical polarity measurement is even worse). This behavior is probably caused by the parasitic elements of the external capacitor used. In fact the $500 \mathrm{pF}$ used in fig. 6e), which gives worse results than the $1 \mathrm{nF}$ used in fig. $6 \mathrm{f}$ ), is the serie connection of two $1 \mathrm{nF}$ capacitor, and this arrangement increases the equivalent serie leakage inductance.

These results are also confirmed by the conducted noise emission measured with a voltage probe Rohde \& Schwarz ESH2-Z5 on the input wires of converter \#1 reported in figs. 9a) and b): the peak around $20 \mathrm{MHz}$ is indicative of some resonances caused by the parasitic elements of the external capacitor. Thus, we can conclude that the improvement caused by a reduced $\mathrm{dv} / \mathrm{dt}$ can be impaired by the external capacitor if it is not opportunely selected.

\section{D) Effects of a hard turn on}

Fig. 7a) shows the radiated noise of converter \#3 at reduced load conditions $\left(\mathrm{I}_{\mathrm{O}}=0.5 \mathrm{~A}\right)$ with the external capacitor $\mathrm{C}_{\mathrm{PEXT}}=500 \mathrm{pF}$ added, so that the ZVS condition is not met. The effect of the increased $\mathrm{dv} / \mathrm{dt}$ at turn on is completely hidden by the lower output power so that the overall noise is lower than that of the same converter with soft switching at full power (fig. 6d).

\section{E) Effects of resonant capacitor $C_{R}$}

The value of the resonant capacitor modifies $i_{L R}$ and $i_{D}$ waveforms during interval $t_{3}-t_{4}$ (see fig. 2) as well as the switch voltage stress. Fig. 7b) reports the noise measured on converter \#2 with $C_{R}=76 n F$. Comparison with fig. $6 \mathrm{c}$ ) shows a better behavior of the converter with higher $C_{R}$ value only for frequencies below $200 \mathrm{MHz}$, while for the vertical field measurement (not shown) the noise is always higher. A possible reason is that lower $C_{R}$ value causes $i_{L R}$ to be much lower at instant $t_{4}$ (see fig. 2), and thus reduces the reverse recovery effect of the freewheeling diode.

\section{CONCLUSIONS}

The soft-switched flyback converter with active clamp is analyzed from the generated electromagnetic noise point of view (EMI). Different design aspects are considered and their impact on conducted and radiated noise investigated.

Based on these measuremets useful design consideration are derived.

\section{REFERENCES}

[1] K. Yoshida, T. Ishii, N. Nagagata, "Zero Voltage Switching Approach for Flyback Converter," INTELEC Conf. Proc., 1992, pp.324-329.

[2] R. Watson, F. C. Lee, G. C. Hua, "Utilization of an Active-Clamp Circuit to Achieve Soft Switching in Flyback Converters," IEEE Power Electronics Specialists' Conf. Rec., 1994, pp. 909-916.

[3] R. Watson, G. C. Hua, F. C. Lee, "Characterization of an Active Clamp Flyback Topology for Power Factor Correction Applications," IEEE Applied Power Electronics Conf. Proc., 1994, pp. 412-418.

[4] G. Spiazzi, L. Rossetto, P. Mattavelli, "Design Optimization of Soft-Switched Insulated DC/DC Converters With Active Voltage Clamp," to be presented at IEEE IAS Conference, San Diego, October, 1996. 


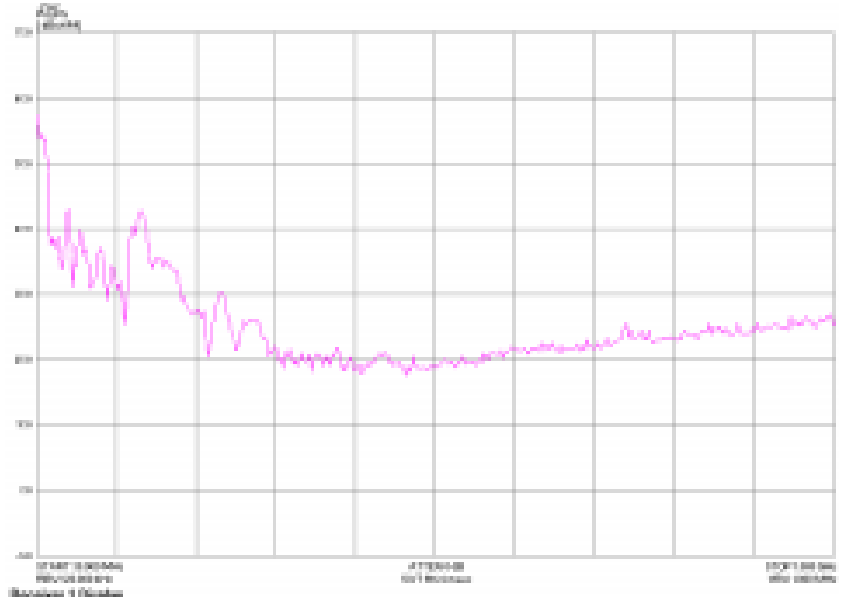

a)

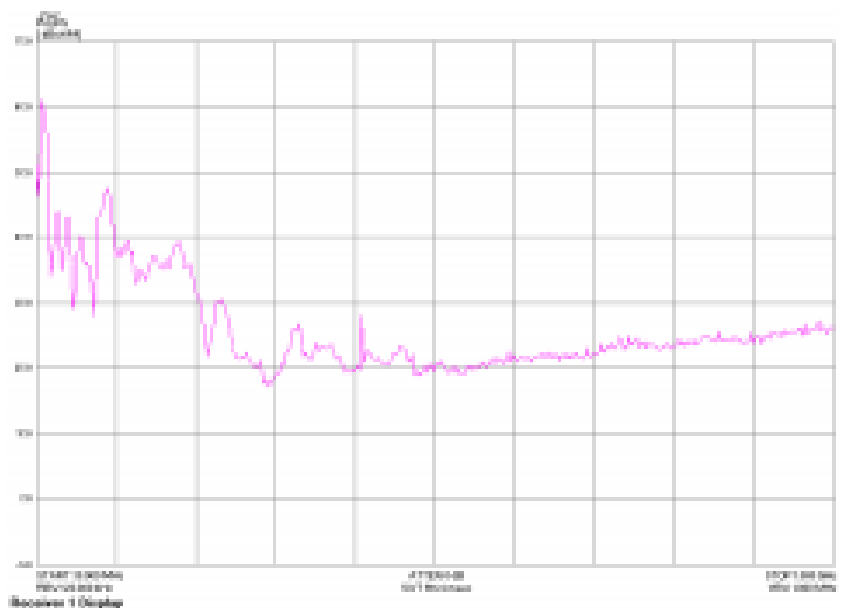

c)

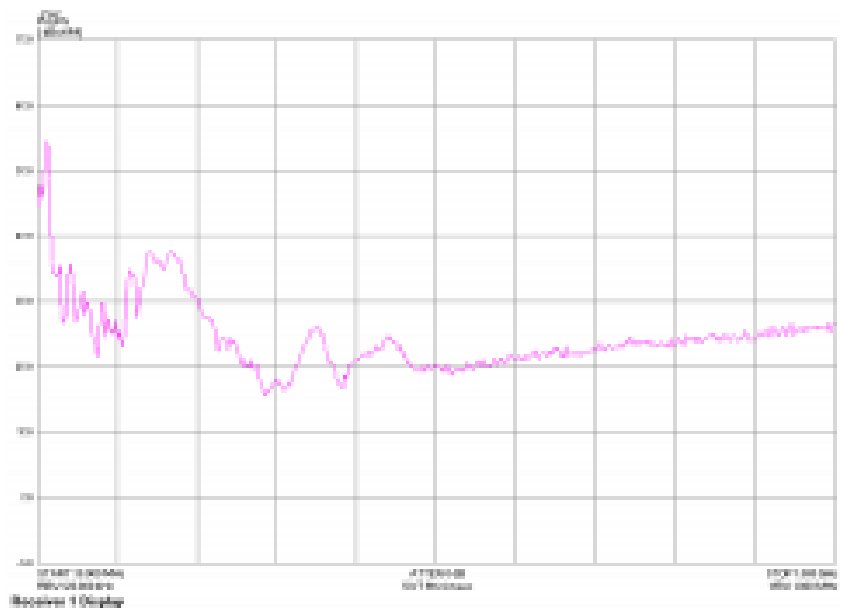

e)

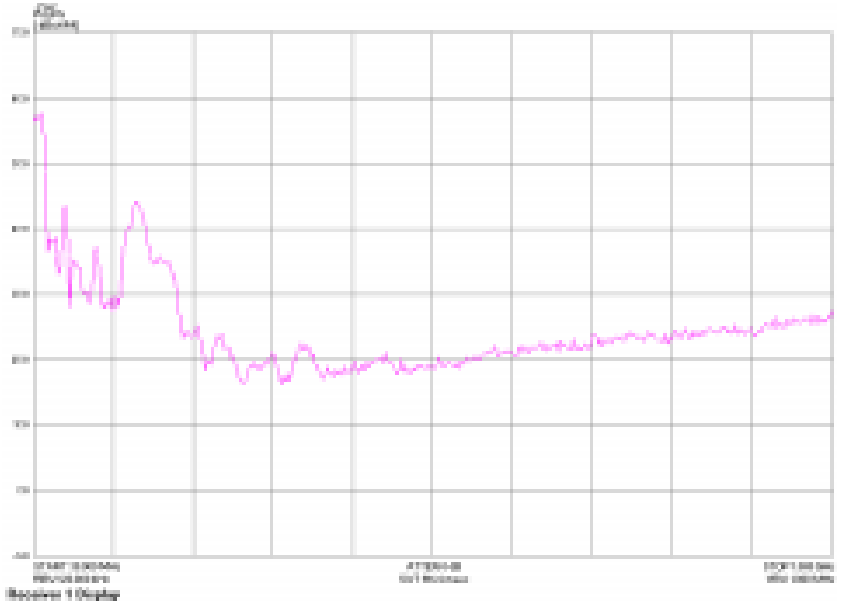

b)

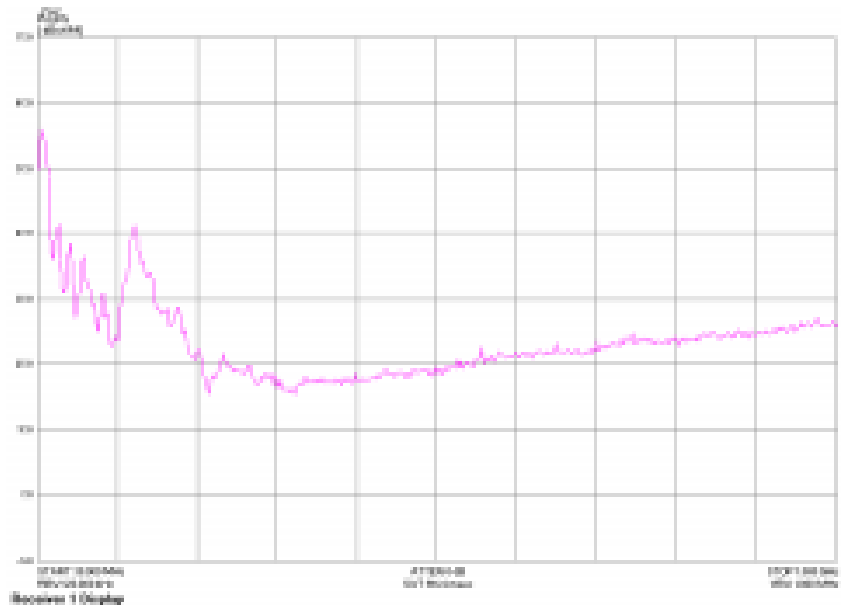

d)

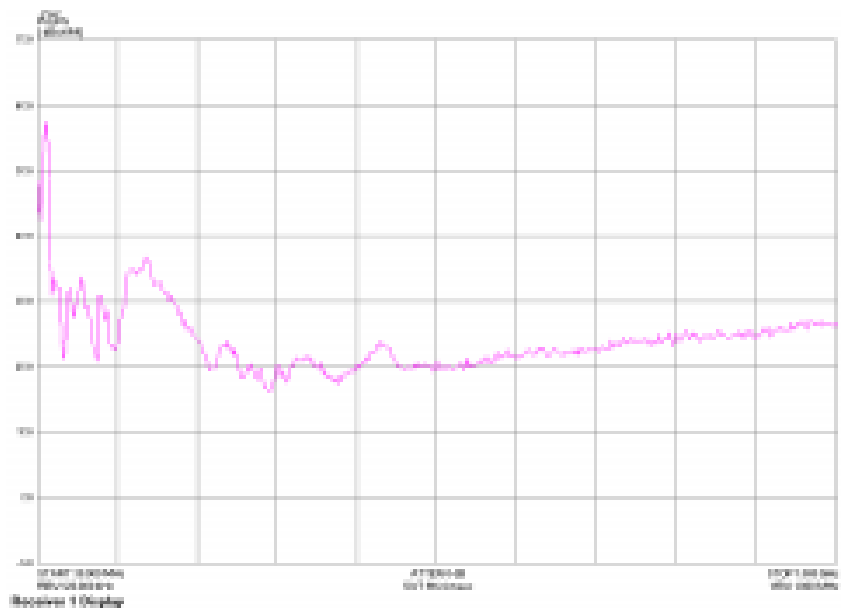

f)

Fig. 6 - Radiated noise (horizontal polarity). Measurement conditions: $\mathrm{V}_{\mathrm{i}}=100 \mathrm{~V}, \mathrm{~V}_{\mathrm{O}}=48 \mathrm{~V}, \mathrm{I}_{\mathrm{O}}=2 \mathrm{~A}(\mathrm{Vert}$ : $10 \mathrm{~dB} \mu$ $\mathrm{V} / \mathrm{M}$ ) a) converter \#1 without secondary snubber; b) converter \#1 with secondary snubber; c) converter \#2 with secondary snubber; d) converter \#3 with secondary snubber; e) converter \#3 with $\mathrm{C}_{\mathrm{PEXT}}=500 \mathrm{pF}$; f) converter \#3 with $\mathrm{C}_{\mathrm{PEXT}}=1 \mathrm{nF}$ 


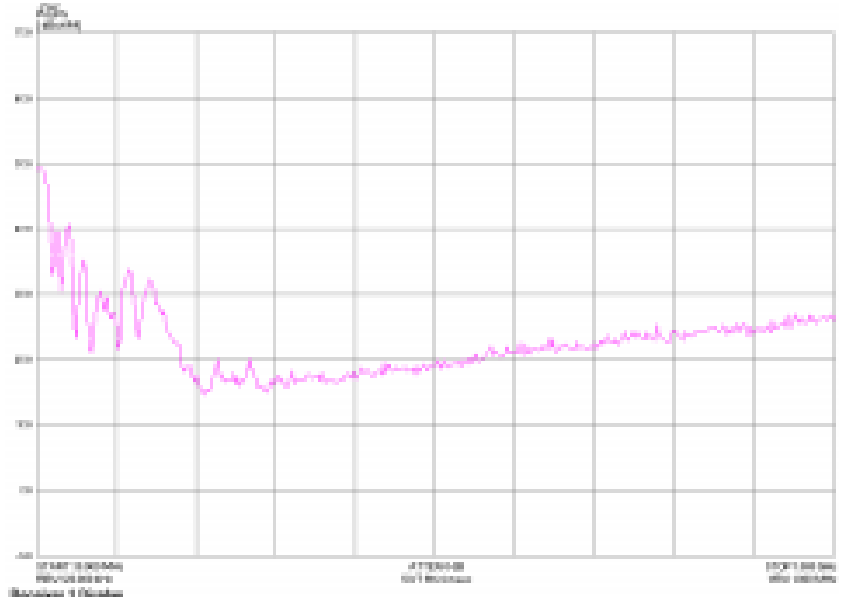

a)

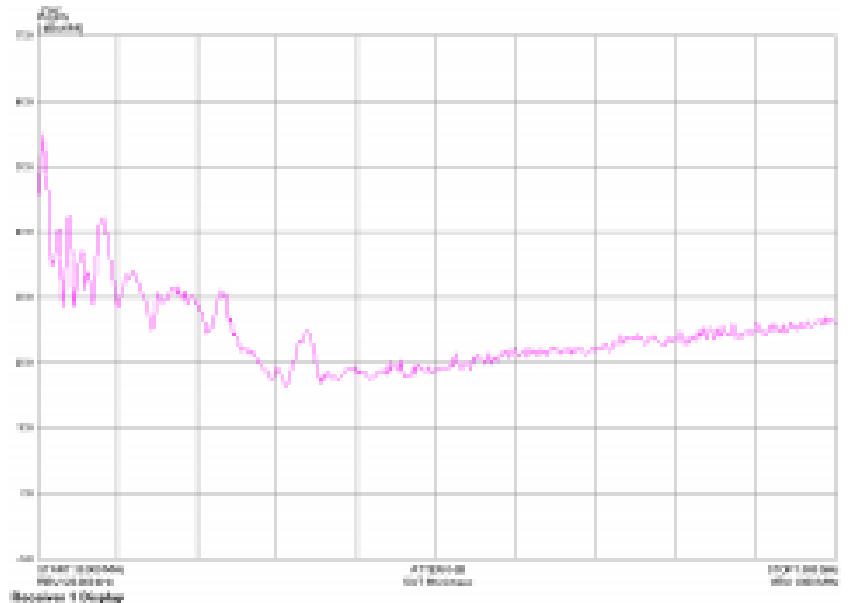

b)

Fig. 7 - Radiated noise (horizontal polarity) (Vert: $10 \mathrm{~dB} \mu \mathrm{V} / \mathrm{M})$. a) converter \#3 with $\mathrm{C}_{\mathrm{PEXT}}=500 \mathrm{pF}$ (measurement cond.: $\mathrm{V}_{\mathrm{i}}=80 \mathrm{~V}, \mathrm{~V}_{\mathrm{O}}=48 \mathrm{~V}, \mathrm{I}_{\mathrm{O}}=0.5 \mathrm{~A}$ ); b) converter $\# 2$ with $\mathrm{C}_{\mathrm{R}}=76 \mathrm{nF}$

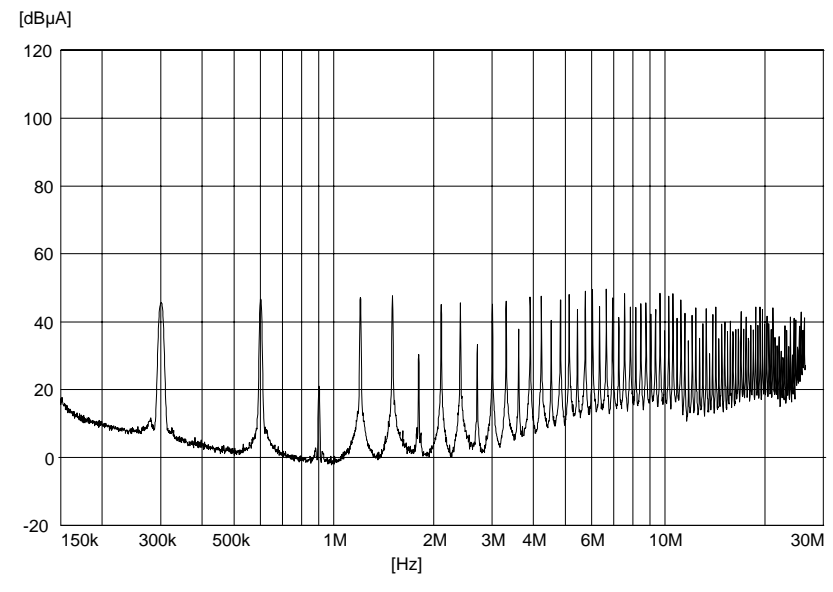

a)

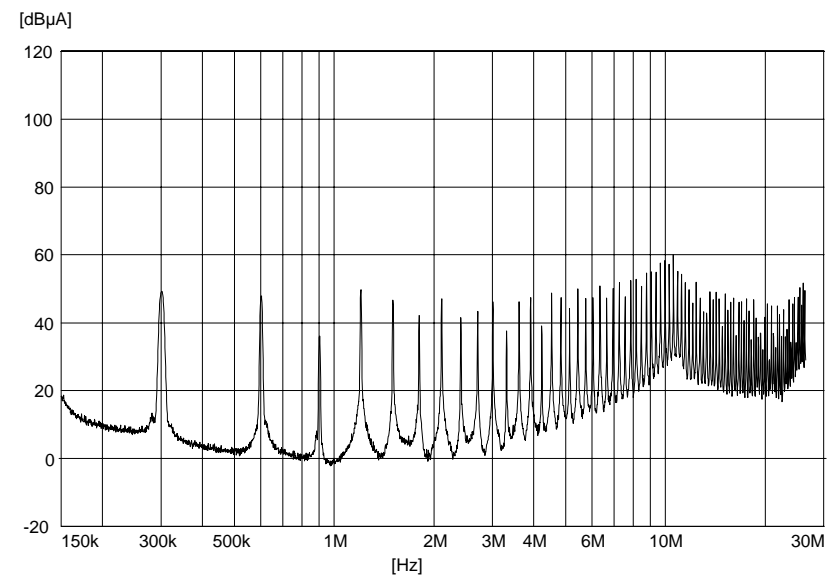

b)

Fig.8 - Measured noise on an output wire of converter \#2; a) with secondary snubber, b) without secondary snubber (Vert: $20 \mathrm{~dB} \mu \mathrm{A})$

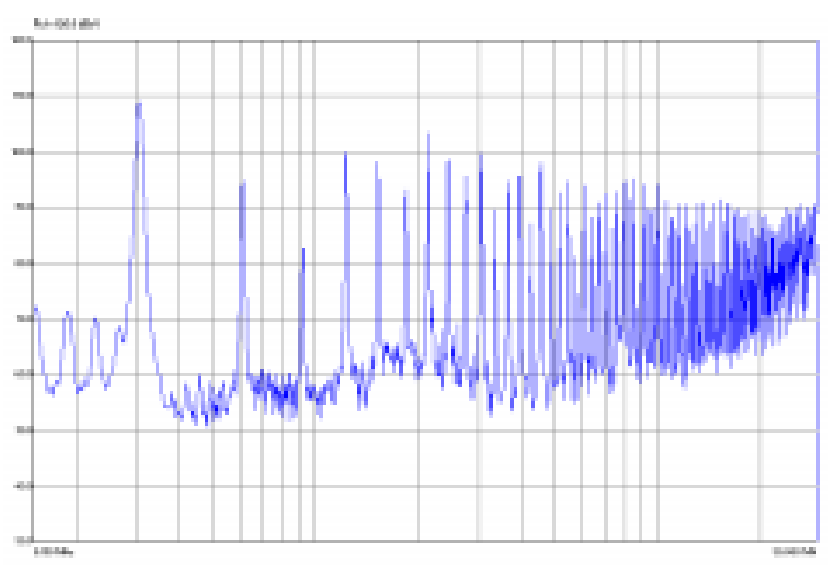

a)

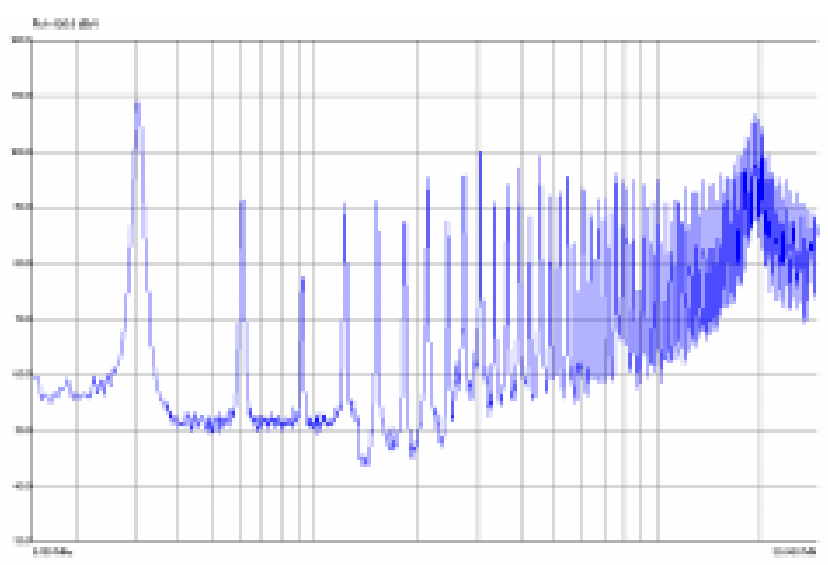

b)

Fig. 9 - Conducted noise. Measurement conditions: $\mathrm{V}_{\mathrm{i}}=100 \mathrm{~V}, \mathrm{~V}_{\mathrm{O}}=48 \mathrm{~V}, \mathrm{I}_{\mathrm{O}}=2 \mathrm{~A},($ Vert: $10 \mathrm{~dB} \mu \mathrm{V})$

a) converter \#1; b) converter \#1 with $\mathrm{C}_{\mathrm{PEXT}}=500 \mathrm{pF}$ 